\title{
IMPACT OF ELECTROMAGNETIC RADIATION EMITTED BY MONITORS ON CHANGES IN THE CELLULAR MEMBRANE STRUCTURE AND PROTECTIVE ANTIOXIDANT EFFECT OF VITAMIN A - IN VITRO STUDY
}

\section{MALGORZATA LEWICKA ${ }^{1}$, GABRIELA HENRYKOWSKA ${ }^{1}$, MAGDALENA ZAWADZKA ${ }^{1}$, MACIEJ RUTKOWSKI ${ }^{2}$, KRZYSZTOF PACHOLSKI ${ }^{3}$, and ANDRZEJ BUCZYŃSKI ${ }^{1}$}

${ }^{1}$ Medical University of Lodz, Łódź, Poland

Epidemiology and Public Health Department

${ }^{2}$ Medical University of Lodz, Łódź, Poland

Department of Military Toxicology and Radiological Protection

${ }^{3}$ Lodz University of Technology, Lódź, Poland

Institute of Electrical Engineering Systems

\begin{abstract}
Objectives: The increasing number of devices emitting electromagnetic radiation (EMR) in people's everyday life attracted the attention of researchers because of possible adverse effects of this factor on living organisms. One of the EMR effect may be peroxidation of lipid membranes formed as a result of free radical process. The article presents the results of in vitro studies aimed at identifying changes in malondialdehyde (MDA) concentration - a marker of lipid peroxidation and antioxidant role of vitamin A during the exposure of blood platelets to electromagnetic radiation generated by liquid-crystal-display (LCD) monitors. Material and Methods: Electromagnetic radiation emitted by LCD monitors is characterized by parameters: $1 \mathrm{kHz}$ frequency and $220 \mathrm{~V} / \mathrm{m}$ intensity $(15 \mathrm{~cm}$ from display screen). The time of exposure was 30 and $60 \mathrm{~min}$. The study was conducted on porcine blood platelets. The samples were divided into 6 groups: unexposed to radiation, unexposed + vitamin A, exposed for $30 \mathrm{~min}$, exposed for $30 \mathrm{~min}+$ vitamin A, exposed for $60 \mathrm{~min}$, exposed for $60 \mathrm{~min}+$ vitamin A. Results: The MDA concentration in blood platelets increases significantly as compared to control values after 60 min of exposure to EMR. A significant decrease in MDA concentration after the addition of vitamin A was noticed. In the blood samples exposed to EMR for 30 and 60 min the MDA concentration was significantly increased by addition of vitamin A. Conclusions: The results show the possibly negative effect of electromagnetic radiation on the cellular membrane structure manifested by changes in malondialdehyde concentration and indicate a possible protective role of vitamin A in this process. Int J Occup Med Environ Health 2017;30(5):695-703
\end{abstract}

Key words:

Lipid peroxidation, Antioxidants, Vitamin A, Malondialdehyde, Electromagnetic radiation, LCD monitors

Received: November 13, 2015. Accepted: December 5, 2016.

Corresponding author: M. Lewicka, Medical University of Lodz, Epidemiology and Public Health Department, Żeligowskiego 7/9, 90-752 Łódź, Poland (e-mail: malgorzata.lewicka@umed.lodz.pl). 


\section{INTRODUCTION}

The technological development that has taken place over the last few years has facilitated daily life and work of people, but at the same time caused new threats to life and health of living organisms to appear in the environment. One of them is the electromagnetic radiation emitted by each device powered by electricity. Numerous studies, concerning the impact of electromagnetic radiation, prove its harmful effects on various organs and tissue function [1-3]. Studies of Mahdavi et al. have reported that extremely low frequency electromagnetic fields (ELF-EMF) may interact with the brain stress system [4].

Available epidemiological evidence suggests an association between occupational exposure to ELF-EMF and Alzheimer's disease [5].

Kim et al. have concluded in animal studies that chronic exposure to ELF-MF may cause adverse effects on the male reproductive system [6].

Mahmoudabadi et al. have concluded that extremely low frequency electromagnetic fields exposure is probably related to early spontaneous abortions. In this case-control study, 58 women who had an unexplained spontaneous abortion at $<14$ weeks gestation and 58 matched pregnant women $>14$ weeks gestation were enrolled in 2012. To evaluate the extremely low frequency electromagnetic fields, researchers determined the magnitude of electromagnetic fields in the participants' houses and it was significantly different between 2 groups [7].

Based on epidemiologic evidence indicated linking ELF exposure to childhood leukemia and evidence for carcinogenicity of ELF in rodent bioassays, the International Agency for Research on Cancer (IARC) classified ELF magnetic fields as a possible human carcinogen (2B classification) [8].

Harmful effects of electromagnetic radiation, on oxygen metabolism of cells, has also been proven by numerous studies [9-12].

Oxidative stress, manifested by an uncontrolled increase in the concentration of reactive oxygen species (ROS), changes in the activity of antioxidant enzymes and initiation of lipid peroxidation's process in the cell membranes is a deleterious process that may be an important mediator of damage to cell structures and consequently various disease states and ageing. Lipid peroxidation of cell membranes is the chain reaction process of cell membranes destruction due to oxidation of nutrients - phospholipids composed of unsaturated fatty acids. The result is excessive synthesis of lipid peroxides and conversion of polyunsaturated fatty acids in biologically active substances, which results in structure and fluidity changes of the cell membrane, disorders of membrane transport, changes in enzyme activity and protein receptors damage in the membrane structures.

The end products of lipid peroxidation is malondialdehyde (MDA) and it may be an indicator of the occurrence of pathological processes, so it's a marker of lipid membrane peroxidation in blood platelets.

A multitude of electromagnetic radiation emitters surrounding people in everyday life and numerous reports of experimental and epidemiological studies regarding the harmfulness of this factor on health has necessitated the creation of norms and principles with regard to prevention activities. One of such activity, though still not giving unequivocal answers about the effectiveness, is supplementation with antioxidant vitamins, for example vitamin A. Thus, the authors of this article have aimed at investigating whether electromagnetic radiation emitted by the liquidcrystal-display (LCD) monitors has influence on the cell membranes damage and if vitamin A has the antioxidant role in this case.

\section{MATERIAL AND METHODS}

\section{Sample preparation}

Pig blood was collected from a slaughterhouses during the exsanguinations of animals. It was taken to $1 \%$ ethylenediaminetetraacetic acid (EDTA). Platelets were obtained by fractionated centrifugation at $1200 \mathrm{rpm} \times \mathrm{g}$ for $10 \mathrm{~min}$ at room temperature. As a result of the cen- 
trifugation, platelet rich plasma (PRP) was obtained from the whole blood, which was carefully pulled by a plastic pipette from the deposited layer of erythrocytes and transferred into polyethylene tubes. Then the obtained platelet rich plasma was centrifuged at $3000 \mathrm{rpm} \times \mathrm{g}$ for $15 \mathrm{~min}$. The precipitated platelets were suspended in $0.2 \mathrm{ml}$ of $0.9 \% \mathrm{NaCl}$. The obtained suspension of blood platelets was an input research model. Each test group consisted of 30 samples which were subjected to the next planned stages of the experiment. Because of the conditions of the hardware each study group was divided into 5 series and made markings of the single stage for 6 samples. The operation was repeated to obtain adequate results for all 30 samples.

In this case (animal intended for food) the approval of the Ethics Commission is not needed.

\section{Incubation of platelets with vitamin A}

An ethanolic solution of vitamin A containing $3 \mathrm{mg}$ of retinol (catalogue No. R7632-25MG, Sigma Life Science, USA) in a volume of $10 \mathrm{ml}$ was used in this study. Two microliters of this solution was added to $0.2 \mathrm{ml}$ of a suspension of blood platelets, avoiding bright light. The sample was incubated in a dark place for $30 \mathrm{~min}$, and then subjected to a further procedure.

\section{Exposure condition setting and instruments}

In a laboratory stand designed for reconstruction of the parameters of electromagnetic radiation generated by display screens $(1 \mathrm{kHz}, 220 \mathrm{~V} / \mathrm{m})$, a flat capacitor was the source of electromagnetic field. Requirements of the Swedish Confederation of Professional Employees (Tjänstemännens Centralorganisation - TCO) [13] specifies strict conditions for the measurement of exposure. Authors measured the field by means of the measurement procedure on the location of points placed in front of the monitor. When electromagnetic radiation of low frequency is tested the electric and magnetic components should be investigated independently. Monitors with liquid crystal screens produce non-sinusoidal electromagnetic fields, with the dominant electric component, due to control of power semiconductor chips.

Significant fields are fields with frequency of the lower power consumption and voltage switching power supply, with superimposed oscillations dampened RLC (resistor, inductor, and capacitor) circuits, which act as voltage ripple smoothing filters. The source of the signal simulating shape of the field generated by the LCD was a programmable generator Hameg 8010, which was amplified by the measuring amplifier W-320, and the source of the electric field was a flat capacitor arrangement.

The capacitor was formed by 2 circular copper plates positioned over and under plastic support. Eight polyethylene tubes containing the tested preparation were inserted into holes in the support. The holes were made symmetrically on the circumference of a circle with the diameter smaller than that of the capacitor plates.

As a result, the electrical component of the field acting on the tubes was homogeneous in nature (Figure 1). The tested preparation was placed in polyethylene tubes, each containing $0.2 \mathrm{ml}$ of the preparation. The temperature in the laboratory stand was on the same level all the time and it was $+24 / 25^{\circ} \mathrm{C}$. Preserving constant conditions of the environment the preparation was exposed to the activity of the electromagnetic field of $1 \mathrm{kHz}$ frequency and $220 \mathrm{~V} / \mathrm{m}$ intensity (corresponding to a distance of $15 \mathrm{~cm}$ from the monitor) for 30 and $60 \mathrm{~min}$. The exposure of the platelets to the radiation was done on the day they were collected from the slaughterhouses.

\section{Measurement of malondialdehyde (MDA) - the marker of membrane lipid peroxidation}

The concentration of malondialdehyde was determined by measuring the absorbance on the spectrophotometer T60 VIS (OMC Envag) at $532 \mathrm{~nm}$ wavelength vs. the control sample $\left(1.8 \mathrm{~cm}^{3}\right.$ phosphate-buffered saline (PBS) + 


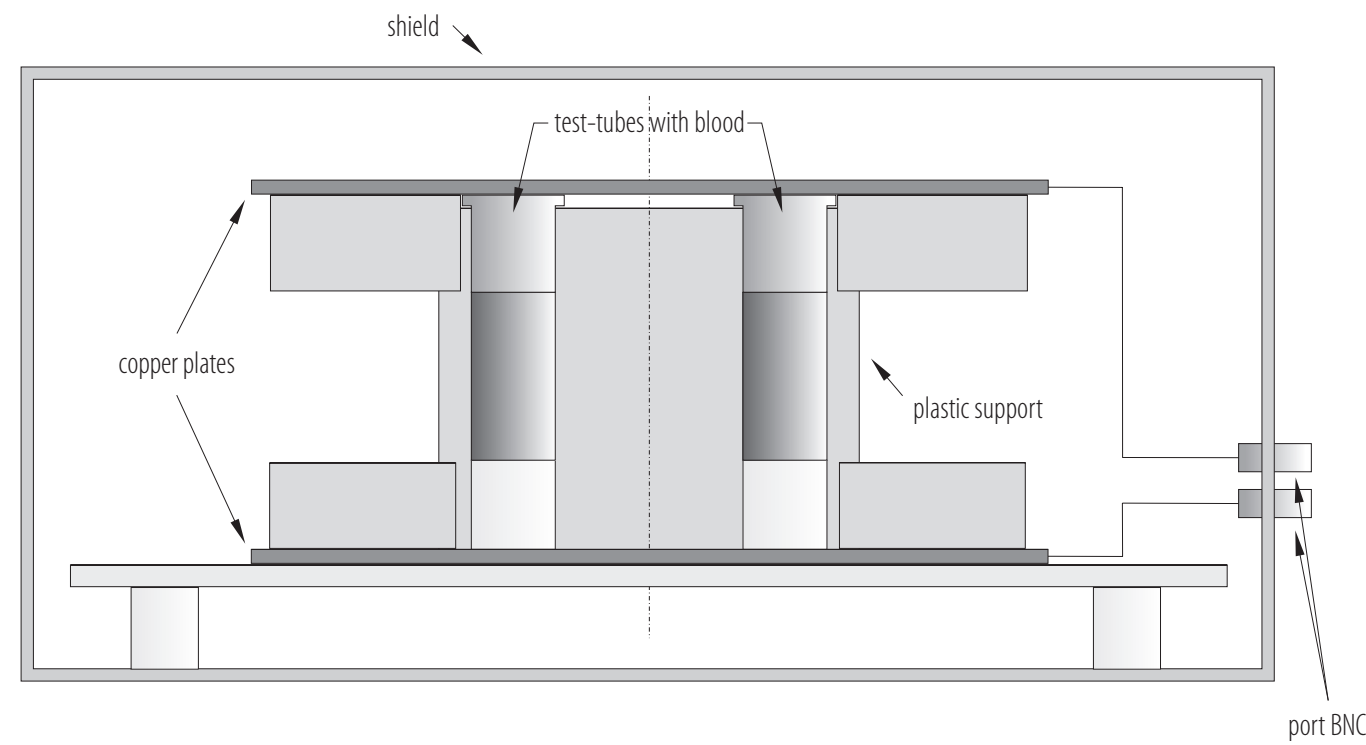

BNC - bayonet Neill-Concelman.

Fig 1. The laboratory stand designed for reconstruction of the parameters of electromagnetic radiation generated by display screens

$0.4 \mathrm{~cm}^{3}$ thiobarbituric acid). The study sample was prepared adding $1 \mathrm{~cm}^{3}$ of $20 \%$ triochloracetic acid (TCA) to $1 \mathrm{~cm}^{3}$ of blood platelet suspension at the concentration of $1 \times 10^{9} / \mathrm{cm}^{3}$. The mixture was shaken for $1 \mathrm{~h}$ at $+4^{\circ} \mathrm{C}$ and centrifuged at $4200 \times \mathrm{g}$ at $+4^{\circ} \mathrm{C}$ for $15 \mathrm{~min}$. To $1.8 \mathrm{~cm}^{3}$ of the obtained supernatant $0.4 \mathrm{~cm}^{3} 0.12 \mathrm{M}$ thiobarbituric acid was added. The mixture was placed in boiling water bath for $15 \mathrm{~min}$. After cooling, the obtained solution was centrifuged at $3000 \times \mathrm{g}$ for $10 \mathrm{~min}$ at room temperature. The obtained results were expressed in $\mathrm{nmol} / 10^{9}$ of platelets [14].

Each sample (from one pig) was divided into 6 fractions and each of them distributed in a different experimental group (unexposed to radiation, unexposed + vitamin A, exposed for $30 \mathrm{~min}$, exposed for $30 \mathrm{~min}+$ vitamin A, exposed for $60 \mathrm{~min}$, exposed for $60 \mathrm{~min}+$ vitamin A). Sample size of each experimental group was 30 .

\section{Statistical analysis}

The following statistical parameters were determined for each characteristics in the study groups: arithmetic mean, standard deviation, median, minimum, maximum, skewness coefficient. The obtained results were analyzed using a nonparametric Kruskal-Wallis ANOVA rank test equivalent to the analysis of variance and Mann-Whitney $U$ test to compare the variables between the groups. The value of $p<0.05$ was considered to be the level of confidence. Calculations were made using the program Statistica PL (license number SN: SP 7105488009G 51).

\section{RESULTS}

In the in vitro studies, the malondialdehyde concentration in blood platelets increases significantly $(p<0.05)$ as compared to control values after $60 \mathrm{~min}$ of exposure to EMF of $220 \mathrm{~V} / \mathrm{m}$ intensity and $1 \mathrm{kV} / \mathrm{m}$ frequency (median: 1.8-2.48). The measurement of malondialdehyde concentration after $30 \mathrm{~min}$ of exposure does not show significant increase (as compared to initial values).

The concentration of malondialdehyde significantly decreases $(p<0.05)$ in the blood sample unexposed to EMF with vitamin $\mathrm{A}$ in comparison with the unexposed sample (median: 1.8-0.97). 
Table 1. Statistical analysis of malondialdehyde (MDA) concentration in blood platelets treated with electromagnetic radiation dependent on exposure time and application of vitamin $\mathrm{A}^{*}$

\begin{tabular}{|c|c|c|c|c|c|}
\hline Variable & M & $\mathrm{Me}$ & Min.-max & $\mathrm{S}$ & $\mathrm{Sk}_{1}$ \\
\hline Control (I) & 1.88 & 1.79 & $1.07-2.91$ & 0.48 & 0.71 \\
\hline Control + vitamin A (II) & 1.12 & 0.97 & $0.73-1.94$ & 0.34 & 1.25 \\
\hline Exposure 30 min (III) & 1.82 & 1.65 & $1.07-2.91$ & 0.60 & 0.43 \\
\hline Exposure 30 min + vitamin A (IV) & 1.07 & 1.09 & $0.49-1.65$ & 0.36 & -0.03 \\
\hline Exposure $60 \min (\mathrm{V})$ & 2.42 & 2.47 & $1.46-3.79$ & 0.66 & 0.40 \\
\hline Exposure 60 min + vitamin $\mathrm{A}(\mathrm{VI})$ & 0.91 & 0.87 & $0.39-1.75$ & 0.37 & 0.54 \\
\hline Kruskal-Wallis Anova rank test & \multicolumn{5}{|c|}{$\mathrm{H}(5, \mathrm{~N}=180)=107.31, \mathrm{p}<0.05$} \\
\hline \multicolumn{6}{|l|}{ Mann-Whitney U test } \\
\hline $\mathrm{Z}^{\mathrm{I}, \mathrm{III}}$ & \multicolumn{5}{|c|}{$\mathrm{Z}^{\mathrm{I}, \mathrm{III}}=0.73, \mathrm{p}>0.05$} \\
\hline $\mathrm{Z}^{\mathrm{I}, \mathrm{V}}$ & \multicolumn{5}{|c|}{$\mathrm{Z}^{\mathrm{I}, \mathrm{V}}=-3.23, \mathrm{p}<0.05$} \\
\hline $\mathrm{Z}^{\mathrm{I}, \mathrm{II}}$ & \multicolumn{5}{|c|}{$\mathrm{Z}^{\mathrm{I}, \mathrm{II}}=5.42, \mathrm{p}<0.05$} \\
\hline $\mathrm{Z}^{\mathrm{IIIIIV}}$ & \multicolumn{5}{|c|}{$\mathrm{Z}^{\mathrm{III}, \mathrm{IV}}=4.53, \mathrm{p}<0.05$} \\
\hline $\mathrm{Z}^{\mathrm{V}, \mathrm{VI}}$ & \multicolumn{5}{|c|}{$\mathrm{Z}^{\mathrm{V}, \mathrm{VI}}=6.49, \mathrm{p}<0.05$} \\
\hline
\end{tabular}

* Number of samples of each test group $=30$.

$\mathrm{M}$ - mean; Me - median; min. - minimal value; max - maximal value; $\mathrm{S}$ - standard deviation; $\mathrm{Sk}_{1}$ - skewness coefficient; $\mathrm{H}$ - value of the KruskalWallis test; Z - value for pair of variables (I, III; I, V; I, II; III, IV; V, VI) of the Mann-Whitney U test.

Malondialdehyde concentration significantly decreases $(p<0.05)$ in the blood sample exposed to EMF for $30 \mathrm{~min}$, to which vitamin A was added as compared with the sample exposed for the same period of time without vitamin A (median: 1.65-1.1).

Malondialdehyde concentration statistically significant decreases in the blood sample exposed to the EMF for $60 \mathrm{~min}$, to which vitamin A was added as compared with the sample exposed for the same period of time without vitamin A (median: 2.48-0.87) (Table 1 and Figure 2).

\section{DISCUSSION}

The multitude of electromagnetic radiation emitters, especially in urban areas, means that contemporary man lives in the so-called electromagnetic smog. Systems of wireless communication, radiolocation and telecommunications, industrial, medical and household equipment are causing an increase in average electromagnetic field strength - a phenomenon not neutral to the health and

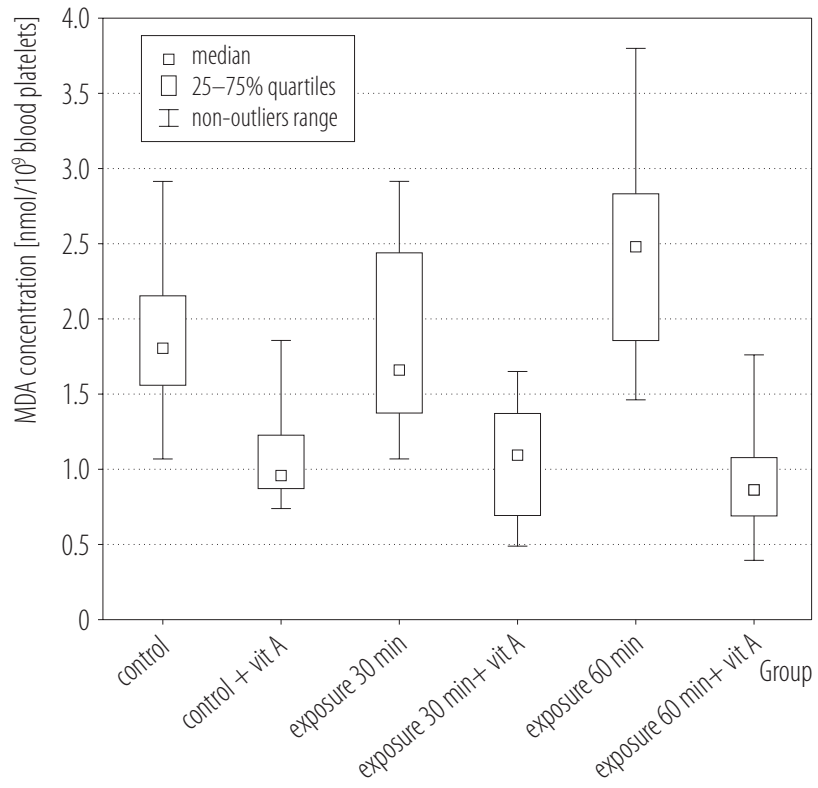

Number of samples of each test group $=30$.

Fig. 2. Changes of malondialdehyde (MDA) concentration in blood platelets exposed to electromagnetic field dependent on exposure time and application of vitamin A 
life of living organisms - which is confirmed in newer and newer publications.

The National Regulatory Research Institute (NRRI) accepted the negative effects of electromagnetic fields on public health as one of the most serious environmental problems.

Displays are devices with which people are in contact since childhood nowadays. The results of researches on the impact of this emitter confirm its harmfulness.

The adverse effects of electromagnetic radiation emitted by the LCD monitors were shown by the epidemiological studies of Korpinen et al. [15]. The respondents had skin symptoms when they stayed in front of a computer screen for a long period [15].

Results of other studies indicate that computer users have more often complained of hearing loss, headaches, vertigo/dizziness, tension - anxiety symptoms, depending on the time of daily usage [16].

The previous study focused on harmful influence of EMR emitted by display screens showing an increase of the MDA concentration in human blood platelets after $30 \mathrm{~min}$ of exposure (in this study significant increase is reported after $60 \mathrm{~min}$ of exposure) [17].

Balci et al.'s [18] experiments conducted on corneal and lens tissue of rats have reported harmful effects of ELFEF. The results of these studies have indicated that this factor may induce oxidative stress manifested among others in an increase of the MDA concentration [18].

Another study indicates that computer radiation may have an adverse effect on total antioxidant capacity (T-AOC) and alkaline phosphates (ALP) content in serum or liver tissue of mice [19].

Moreover, the research on the effects of electromagnetic radiation emitted by other devices, but also as LCD monitors of low and extremely low frequency (ELF-EF), indicates a negative effect on the oxidative metabolism of various cells and tissues.

The results of Canseven et al. studies have shown that electromagnetic fields of low frequency $(50 \mathrm{~Hz}$ frequency and 1, 2 and $3 \mathrm{mT}$ induction) have an influence on increasing formation of ROS and changes in antioxidant enzyme activity in tissues of the heart and the liver of guinea pigs [20].

Another study has demonstrated that the low frequency electromagnetic fields generated by car electronics, physiotherapy equipment and LCD monitors may be the cause of oxidative stress in the human body. During this experiment an increase in catalase activity and MDA concentration is observed after 30 min exposure of platelets to EMF regardless of the radiation source [21]. The obtained results are similar to the ones as the outcome of this study excluding the observation time (our study has indicated increase in MDA concentration after 60 min exposure and insignificant increase after 30 min exposure).

Studies of Goraca et al. on the electromagnetic radiation with the frequency of $40 \mathrm{~Hz}$ and $7 \mathrm{mT}$ induction used for $60 \mathrm{~min} /$ day for 14 days show significant increase in thiobarbituric acid reactive substances (TBARS) in rats' heart [22]. A significant increase in TBARS concentration (a marker of lipid peroxidation) has also been observed by scientists subjecting the action of low frequency electromagnetic field of the liver of a mouse [22].

Our study also shows an increase in MDA after 60 min of exposure to electromagnetic radiation emitted by LCD monitors. It proves insufficient adaptation of cellular antioxidant capacity which protects, among others, against oxidation of cell membrane components.

The above-mentioned and many other similar scientific reports have forced researchers to pose the questions about the effectiveness of preventive activities protecting people against the effects of EMF leading to oxidative stress. The effectiveness of antioxidants such as vitamin $\mathrm{C}$ and $\mathrm{E}$ are undeniably confirmed by numerous studies [19,24,25]. In contrast, the results of a study on vitamin $\mathrm{A}$ and its provitamin - $\beta$-carotene stir up controversies among researchers. Vitamin and provitamin A play a similar role as protective vitamin E. Carotenoids prove to be capable 
of removing singlet oxygen $\left({ }^{1} \mathrm{O}_{2}\right)$ as well as potent scavengers of other reactive oxygen species thus protecting cells against cancer and aging, among others [26].

It has also been found that the concentration of $\beta$-carotene and other carotenoids, such as lutein, zeaxanthin, lycopene, $\beta$-cryptoxanthin, $\alpha$-carotene is reduced with age, while the concentration of vitamin $\mathrm{A}$ is increased in the case of people over a hundred years old [27]. At the same time, other studies have shown that $\beta$-carotene in high doses in the case of smokers increases the incidence of lung cancer and increases mortality [28]. The findings presented by the authors indicate a preventive antioxidant role of vitamin A in the case of exposure to EMF emitted by LCD monitors.

In this study, the authors have observed changes in the malondialdehyde concentration in the pork blood samples after the addition of vitamin A. When comparing samples of control material - not exposed to EMF (control vs. control + vitamin A) a significant decrease in MDA concentration after the addition of this vitamin has been noticed.

In the blood samples exposed to EMF for $30 \mathrm{~min}$ and 60 min the MDA concentration is significantly decrease by addition of vitamin $\mathrm{A}$.

Vitamin A is a fat-soluble that may pass into the cell and may sweep up the free radicals which are formed inside the cell, and those formed in the cell membrane. The reduced concentration of malondialdehyde in the test samples may be explained by the fact that through the antioxidant action of vitamin A the amount of free radicals goes down, which in turn results in partial inhibition of the destruction of cell membranes by lipid peroxidation. In effect, the measurement of the concentration of MDA - the final product of peroxidation of cell membranes - exhibits its significant decline.

The changes of malondialdehyde concentration in our study may indicate the negative effect of the used radiation and the protective antioxidant role of vitamin A.
The presented results of these and other authors should suggest an important preventive role of vitamins $\mathrm{A}, \mathrm{C}$ and $\mathrm{E}$ to protect against the effects of electromagnetic radiation which we are exposed to in everyday life.

\section{CONCLUSIONS}

The in vitro study has demonstrated that the exposure to EMF emitted by LCD monitors changes the malondialdehyde (MDA) concentration, a marker of lipid peroxidation in blood platelets. After $60 \mathrm{~min}$ irradiation of field of $220 \mathrm{~V} / \mathrm{m}$ intensity, the MDA concentration increases relatively to the control value.

The findings indicate that exposure to electromagnetic radiation of $1 \mathrm{kHz}$ frequency and $220 \mathrm{~V} / \mathrm{m}$ intensity may cause adverse effects within blood platelets oxygen metabolism and thus may lead to an organism physiological dysfunction (with emphasis that the results are reliable in vitro study and cannot be directly extrapolate for living organisms).

The observed changes in the MDA concentration in the pork blood samples after the addition of vitamin A may indicate the protective antioxidant role of vitamin $\mathrm{A}$.

\section{REFERENCES}

1. Duan W, Liu C, Zhang L, He M, Xu S, Chen C, et al. Comparison of the genotoxic effects induced by $50 \mathrm{~Hz}$ extremely low-frequency electromagnetic fields and $1800 \mathrm{MHz}$ radiofrequency electromagnetic fields in GC-2 cells. Radiat Res. 2015;183(3):305-14, https://doi.org/10.1667/RR13851.1.

2. Baldi I, Coureau G, Jaffre A, Gruber A, Ducamp S, Provost D, et al. Occupational and residential exposure to electromagnetic fields and risk of brain tumors in adults: A case-control study in Gironde, France. Int J Cancer. 2011;129(6):1477-84, https://doi.org/10.1002/ijc.25765.

3. Liu X, Zhao L, Yu D, Ma S, Liu X. Effects of extremely low frequency electromagnetic field on the health of workers in automotive industry. Electromagn Biol Med. 2013;32(4): 551-9, https://doi.org/10.3109/15368378.2013.773909. 
4. Mahdavi SM, Sahraei H, Yaghmaei P, Tavakoli H. Effects of electromagnetic radiation exposure on stress-related behaviors and stress hormones in male Wistar rats. Biomol Ther (Seoul). 2014;22(6):570-6, https://doi.org/10.4062/biomolther.2014.054.

5. Garcia AM, Sisternas A, Hoyos SP. Occupational exposure to extremely low frequency electric and magnetic fields and Alzheimer disease: A meta-analysis. Int J Epidemiol. 2008;37(2):329-40, https://doi.org/10.1093/ije/dym295.

6. Kim HS, Park BJ, Jang HJ, Ipper NS, Kim SH, Kim YJ, et al. Continuous exposure to $60 \mathrm{~Hz}$ magnetic fields induces duration- and dose-dependent apoptosis of testicular germ cells. Bioelectromagnetics. 2014;35(2):100-7, https:/doi. org/10.1002/bem.21819.

7. Mahmoudabadi SF, Ziaei S, Firoozabadi M, Kazemnejad A. Exposure to extremely low frequency electromagnetic fields during pregnancy and the risk of spontaneous abortion: A case-control study. J Res Health Sci [Internet]. 2013 [cited 2015 Oct 1];13(2):131-4. Available from: http://jrhs.umsha. ac.ir/index.php/JRHS/article/view/848/html.

8. International Agency for Research on Cancer (IARC). IARC monographs on the evaluation of carcinogenic risks to humans, Vol. 80. Non-ionizing radiation, Part 1: Static and extremely low-frequency (ELF) electric and magnetic fields [Internet]. Lyon: IARC Press; 2002 [cited 2015 Oct 1]. Available from:http://monographs.iarc.fr/ENG/Monographs/ vol80/mono80.pdf.

9. Sharifian A, Gharavi M, Pasalar P, Aminian O. Effect of extremely low frequency magnetic field on antioxidant activity in plasma and red blood cells in spot welders. Int Arch Occup Environ Health. 2009;82:259-66, https://doi.org/10.1007/ s00420-008-0332-2.

10. Kovacic P, Somanathan R. Electromagnetic fields: Mechanism, cell signaling, other bioprocesses, toxicity, radicals, antioxidants and beneficial effects. J Recept Signal Transduct Res. 2010;30(4):214-26, https://doi.org/10.3109/10799893.20 10.488650 .

11. Agarwal A, Singh A, Hamada A, Kesari K. Cell phones and male infertility: A review of recent innovations in technology and consequences. Int Braz J Urol. 2011;37:432-54, https:// doi.org/10.1590/S1677-55382011000400002.

12. Burlaka A, Tsybulin O, Sidorik E, Lukin S, Polishuk V, Tsehmistrenko S, et al. Overproduction of free radical species in embryonal cells exposed to low intensity radiofrequency radiation. Exp Oncol [Internet]. 2013 [cited 2015 Oct 1];35(3):219-25. Available from: http://exp-oncology. com.ua/article/6079.

13. TCO Development. TCO Certified Displays 7.0 [Internet]. Stockholm: TCO Development; 2015 [cited 2015 Oct 1]. Available from: http://tcocertified.com/files/2015/11/TCOCertified-Displays-7.0.pdf.

14. Placer Z, Cushman LL, Johnson BC. Estimation of products of lipid peroxidation (malonyl dialdehyde) in biochemical systems. Anal Biochem. 1966;16:359-64, https://doi. org/10.1016/0003-2697(66)90167-9.

15. Korpinen LH, Paakkonen RJ. Self-report of physical symptoms associated with using mobile phones and other electrical devices. Bioelectromagnetics. 2009;30(6):431-7, https:// doi.org/10.1002/bem.20500.

16. Kucer N, Pamukcu T. Self-reported symptoms associated with exposure to electromagnetic fields: A questionnaire study. Electromagn Biol Med. 2014;33(1):15-7, https://doi. org/10.3109/15368378.2013.783847.

17. Lewicka M, Henrykowska GA, Pacholski K, Śmigielski J, Rutkowski M, Dziedziczak-Buczyńska M, et al. The effect of electromagnetic radiation emitted by display screens on cell oxygen metabolism - In vitro studies. Arch Med Sci. 2015;11(6):1330-9, https://doi.org/10.5114/aoms.2015.56362.

18. Balci M, Namuslu M, Devrim E, Durak I. Effects of computer monitor-emitted radiation on oxidant/antioxidant balance in cornea and lens from rats. Mol Vis [Internet]. 2009 [cited 2015 Oct 1];15:2521-5. Available from: http://www.molvis. org/molvis/v15/a270.

19. Pei X, Gu Q, Ye D, Wang Y, Zou X, He L, et al. Effect of computer radiation on weight and oxidant-antioxidant status of mice. Nutr Hosp. 2015;31(3):1183-6, https://doi.org/ 10.3305/nh.2015.31.3.8200. 
20. Canseven AG, Coskun S, Sevhan N. Effects of various extremely low frequency magnetic fields on the free radical processes, natural antioxidant system and respiratory burst system activities in the heart and liver tissues. Indian J Biochem Biophys [Internet]. 2008 [cited 2015 Oct 1];5:326-31. Available from: http://nopr.niscair.res.in/bitstream/1234567 89/2374/1/IJBB45(5)326-331.pdf.

21. Lewicka M, Henrykowska GA, Pacholski K, Szczęsny A, Dziedziczak-Buczyńska M, Buczyński A. The impact of electromagnetic radiation of different parameters on platelet oxygen metabolism - In vitro studies. Adv Clin Exp Med. 2015;24(1):31-5, https://doi.org/10.17219/acem/38169.

22. Gorąca A, Ciejka E, Piechota A. Effects of extremely low frequency magnetic field on the parameters of oxidative stress in heart. J Physiol Pharmacol [Internet]. 2010 [cited 2015 Oct 1];61(3):333-8. Available from: http://www.jpp. krakow.pl/journal/archive/06_10/pdf/333_06_10_article.pdf.

23. Hashish AH, El-Missiry MA, Abdelkader HI, AbouSaleh RH. Assessment of biological changes of continuous whole body exposure to static magnetic field and extremely low frequency electromagnetic fields in mice. Ecotoxicol Environ Saf. 2008;71(3):895-902, https://doi.org/10.1016/ j.ecoenv.2007.10.002.
24. Jelodar G, Nazifi S, Akbari A. The prophylactic effect of vitamin $\mathrm{C}$ on induced oxidative stress in rat testis following exposure to $900 \mathrm{MHz}$ radio frequency wave generated by a BTS antenna model. Electromagn Biol Med. 2013;32(3): 409-16, https://doi.org/10.3109/15368378.2012.735208.

25. Al-Damegh MA. Rat testicular impairment induced by electromagnetic radiation from a conventional cellular telephone and the protective effects of the antioxidants vitamins C and E. Clinics. 2012;67(7):785-92, https://doi.org/ 10.6061/clinics/2012(07)14.

26. Edge R, Truscott G. Properties of carotenoid radicals and excited states and their potential role in biological systems. In: Landrum JT, editor. Carotenoids: Physical, chemical, and biological functions and properties [Internet]. Boca Raton: CRC Press; 2010 [cited 2015 Oct 1]. p. 283-307. Available from: https://doi.org/10.1201/9781420052312-c14.

27. Mecocci P, Polidori MC, Troiano L, et al. Plasma antioxidant and longevity: A study on healthy centenarians. Free Radic Biol Med. 2000;28:1243-48, https://doi.org/10.1016/S08915849(00)00246-X.

28. Góralczyk R. $\beta$-Carotene and lung cancer in smokers: Review of hypotheses and status of research. Nutr Cancer. 2009;61:767-74, https://doi.org/10.1080/01635580903285155.

This work is available in Open Access model and licensed under a Creative Commons Attribution-NonCommercial 3.0 Poland License - http://creativecommons.org/ licenses/by-nc/3.0/pl/deed.en. 